\title{
In vitro assembly of the bacterial actin protein MamK from 'Candidatus Magnetobacterium casensis' in the phylum Nitrospirae
}

\author{
Aihua Deng ${ }^{1}$, Wei Lin $^{2}$, Nana Shi ${ }^{1}$, Jie $\mathrm{Wu}^{1,3}$, Zhaopeng Sun ${ }^{1,3}$, Qinyun Sun ${ }^{1,3}$, Hua Bai ${ }^{1,3}$, Yongxin Pan ${ }^{2}$, \\ Tingyi Wen ${ }^{1 凶}$ \\ ${ }^{1}$ CAS Key Laboratory of Pathogenic Microbiology and Immunology, Institute of Microbiology, Chinese Academy of Sciences, \\ Beijing 100101, China \\ 2 Biogeomagnetism Group, Paleomagnetism and Geochronology Laboratory, Key Laboratory of Earth and Planetary Physics, \\ Institute of Geology and Geophysics, Chinese Academy of Sciences, Beijing 100029, China \\ ${ }^{3}$ University of Chinese Academy of Sciences, Beijing 100049, China \\ $\triangle$ Correspondence: wenty@im.ac.cn (T. Wen)
}

Received February 4, 2016 Accepted February 7, 2016

\begin{abstract}
Magnetotactic bacteria (MTB), a group of phylogenetically diverse organisms that use their unique intracellular magnetosome organelles to swim along the Earth's magnetic field, play important roles in the biogeochemical cycles of iron and sulfur. Previous studies have revealed that the bacterial actin protein MamK plays essential roles in the linear arrangement of magnetosomes in MTB cells belonging to the Proteobacteria phylum. However, the molecular mechanisms of multiple-magnetosome-chain arrangements in MTB remain largely unknown. Here, we report that the MamK filaments from the uncultivated 'Candidatus Magnetobacterium casensis' (Mcas) within the phylum Nitrospirae polymerized in the presence of ATP alone and were stable without obvious ATP hydrolysis-mediated disassembly. MamK in Mcas can convert NTP to NDP and NDP to NMP, showing the highest preference to ATP. Unlike its Magnetospirillum counterparts, which form a single magnetosome chain, or other bacterial actins such as MreB and ParM, the polymerized MamK from Mcas is independent of metal ions and nucleotides except for ATP, and is assembled into well-ordered filamentous bundles consisted of multiple filaments. Our results suggest a dynamically stable assembly of MamK
\end{abstract}

Electronic supplementary material The online version of this article (doi:10.1007/s13238-016-0253-x) contains supplementary material, which is available to authorized users. from the uncultivated Nitrospirae MTB that synthesizes multiple magnetosome chains per cell. These findings further improve the current knowledge of biomineralization and organelle biogenesis in prokaryotic systems.

KEYWORDS magnetotactic bacteria, Nitrospirae, bacterial actin, MamK, assembly mechanism

\section{INTRODUCTION}

Cytoskeletal proteins have been identified in all organisms as a basic structural framework. They are critical for many important cellular processes, such as cell growth, shape maintenance, cell division, motility and internal transport pathways (Pollard and Cooper, 2009; Shih and Rothfield, 2006; Cabeen and Jacobs-Wagner, 2005, 2010). Among these proteins, actin is one of the most abundant and highly conserved proteins in most eukaryotic cells. Recent studies, however, have demonstrated that actins are also present in prokaryotic cells and have multiple functions ranging from the maintenance of cell shape to the organization of subcellular structures (Ozyamak et al., 2013a; Carballido, 2006). To date, approximately 40 different actin protein families sharing less than $30 \%$ identity have been discovered in prokaryotic organisms (Derman et al., 2009). Despite their low sequence identities, all bacterial actin proteins contain a similar tertiary structure and a common ATP-binding pocket (Carballido, 2006). However, unlike their eukaryotic counterparts bacterial actin proteins possess unique physical functions and biochemical and structural features (Ozyamak 
et al., 2013a). Moreover, bacterial actins are divided into distant families according to their physical functions, and the protein sequences of families from different sources are highly divergent. MreB, ParM, FtsA and MamK form four phylogenetically and functionally distinct groups of bacterial actin proteins and play vital roles in controlling cell shape (Reimold et al., 2013), segregating plasmid DNA (Garner et al., 2004), dividing cells (Szwedziak et al., 2012) and organizing the subcellular magnetosome chain structure (Komeili et al., 2006), respectively (Fig. 1).

Magnetosomes are intracellular nano-sized membraneenveloped magnetite $\left(\mathrm{Fe}_{3} \mathrm{O}_{4}\right)$ and/or greigite $\left(\mathrm{Fe}_{3} \mathrm{~S}_{4}\right)$ minerals that are normally organized into one or multiple chain structures in magnetotactic bacteria (MTB) (Bazylinski et al., 2013a). This chain arrangement confers the ability to sense the Earth's magnetic field to MTB and facilitates the orientation of these bacteria to low-oxygen microhabitats (Faivre and Schüler, 2008). Magnetosome chains in MTB are attractive model systems for investigating the molecular mechanisms of organelle-like structure formation in prokaryotic cells (Schüler, 2008; Cornejo et al., 2014). The formation of magnetosomes is under strict genetic control through a group of magnetosome-associated proteins involved in magnetosome membrane biogenesis, magnetosome biomineralization and

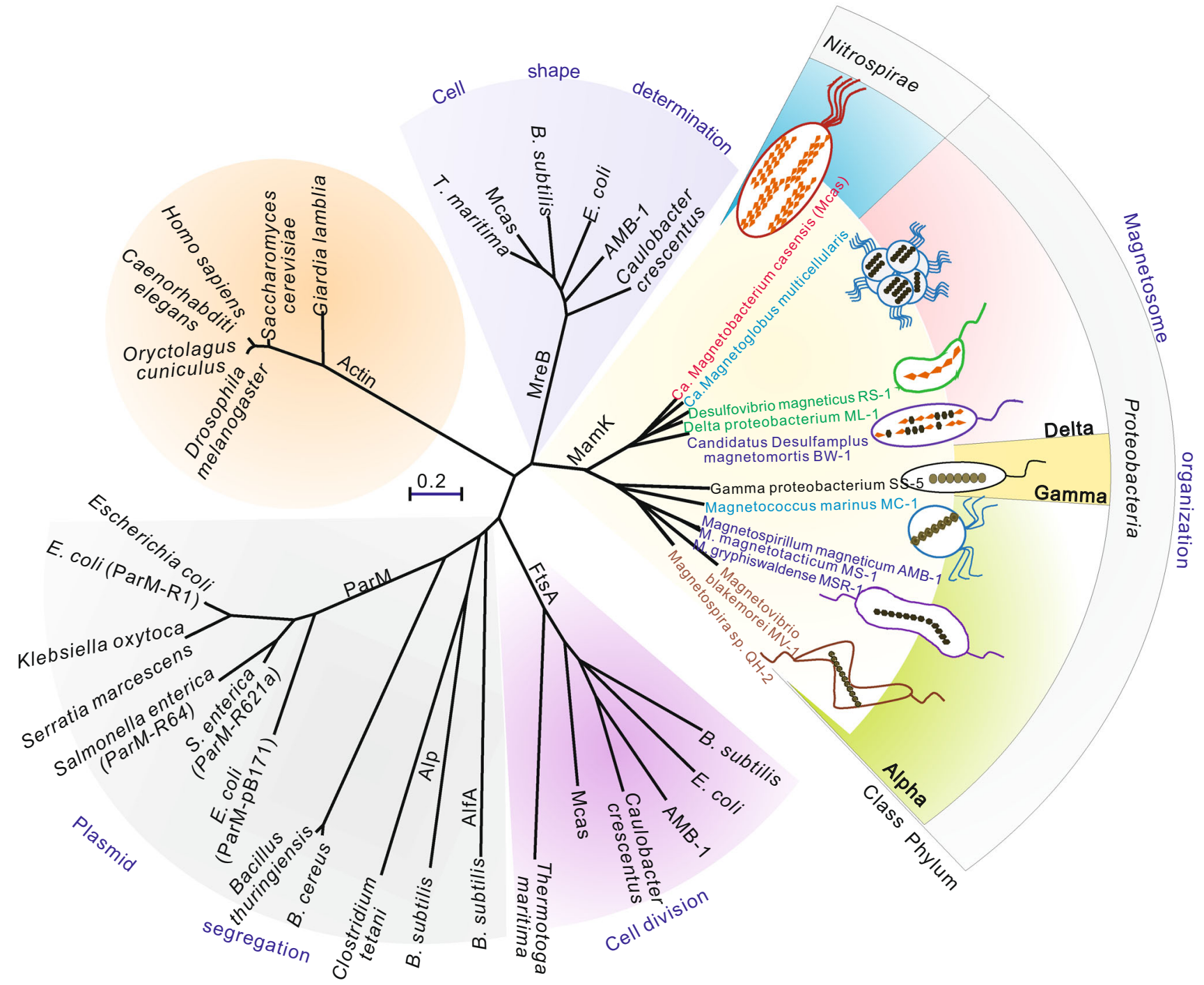

Figure 1. Phylogenetic tree based on amino acid sequences of actin-like and closely related proteins found in bacteria. The eukaryotic actin proteins from distinct sources including Saccharomyces cerevisiae, Caenorhabditis elegans, Giardia lamblia, Drosophila melanogaster, Oryctolagus cuniculu and Homo sapiens were used to root the tree. The MamK proteins from cultured and uncultured magnetotactic bacteria that have known magnetosome structures clustered into two groups. Accession numbers are given in Table S1. The tree is based on a maximum likelihood algorithm. The bar represents $20 \%$ sequence divergence. 
magnetosome membrane chain arrangement (Rahn and Komeili, 2013; Kolinko et al., 2014; Murat et al., 2010). Bacteria that form magnetosomes have been thus far detected in the Alphaproteobacteria, Deltaproteobacteria and Gammaproteobacteria classes of the Proteobacteria phylum, the phylum Nitrospirae and the candidate division OP3 (Lin et al., 2014a). It was recently reported that some members of the candidate phylum Latescibacteria have the genetic potential for greigite magnetosome formation (Lin and Pan, 2015). Magnetosomes in Magnetospirillum from the Alphaproteobacteria are flanked by a series of cytoskeletal filaments consisting of MamK proteins, which are assembled into a well-organized chain structure (Komeili et al., 2006; Katzmann et al., 2010; Draper et al., 2011). In the absence of MamK, the cytoskeletal filaments in Magnetospirillum disappear and the chain formation/structure changes. In $M$. magneticum AMB-1 (AMB-1), the mamK deletion mutant lacks the long and highly organized magnetosome chains observed in the wild-type strain (Komeili et al., 2006). The loss of mamK in M. gryphiswaldense MSR-1 (MSR1) results in shorter, fragmented and ectopic chains (Katzmann et al., 2010). Moreover, MamK in MSR-1 plays a role in the magnetosome chain recruitment to the cell division site (Lin and Pan, 2011; Katzmann et al., 2011). Several studies have shown that MamK from Magnetospirillum forms filaments in vitro as well (Sonkaria et al., 2012; Taoka et al., 2007; Ozyamak et al., 2013b). These results suggest that MamK plays a crucial role in the formation and genetic stability of magnetosome chains.

To date, all known MamK proteins form two distinct groups (Fig. 1). One group includes MamK from the Alphaproteobacteria and Gammaproteobacteria, in which cuboidal/elongated magnetosomes are arranged into single chains in each cell (Lefèvre et al., 2012; Bazylinski et al., 2013b; Zhu et al., 2010; Bazylinski et al., 2013c; Lefèvre and Bazylinski, 2013). Among this group, the in vitro biochemical properties and assembly behaviours of MamK proteins from three closely related Magnetospirillum species have been extensively studied (Sonkaria et al., 2012; Taoka et al., 2007; Ozyamak et al., 2013b). They have nucleotide hydrolysis activities and assemble into filaments. However, MamK proteins from MSR-1 (Taoka et al., 2007), AMB-1 (Ozyamak et al., 2013b) and $M$. magnetotacticum MS-1 (MS-1) (Ozyamak et al., 2013b) have displayed diverse behaviours, including the role in nucleotides and filament assembly, which suggests a biochemical and functional variation in MamK proteins from different species.

MamK proteins from the Deltaproteobacteria and Nitrospirae phylum that arrange bullet-shaped or irregular magnetosomes into single or multiple chain(s) (Lefèvre and Wu, 2013; Jogler et al., 2011; Lin et al., 2014b; Lefèvre et al., 2011) clustered into another group (Fig. 1). Because more complex and intricate three-dimensional organizations of the multiple magnetosome strands are present in 'Candidatus Magnetobacterium bavaricum' (Mbav) (Jogler et al., 2011) and 'Ca. Magnetobacterium casensis' (Mcas) (Lin et al., 2014b) in the Nitrospirae phylum, the structure and function of the magnetosome cytoskeleton in these bacteria are speculated to be distinct from those of the MamK cytoskeleton in Magnetospirillum species. However, due to a lack of pure cultures, the current knowledge of biochemical properties of MamK proteins in the latter group remains very limited.

Recently, the draft genome of an uncultivated Nitrospirae MTB strain Mcas was recovered (Lin et al., 2014b). Mcas forms hundreds of bullet-shaped magnetite magnetosomes arranged into multiple bundles of chains within a single cell. The genome contains a magnetosome gene cluster with a complete mamK gene and other magnetosome-associated genes responsible for the formation of bullet-shaped multiple-chain magnetosomes. The MamK protein (GenBank accession AIM41328) in Mcas is $~ 40 \%$ identical to that of the Magnetospirillum species and contains the similar ATPase binding motifs conserved in all bacterial actin proteins (Lin et al., 2014b). In the present study, we characterized the in vitro biochemical properties and assembly behaviour of Mcas MamK.

\section{RESULTS}

Nucleotide substrate preference and hydrolysis reaction processes of MamK

MamK from Mcas exhibited a broad substrate spectrum and could hydrolyze various nucleotides (ATP, GTP, ADP and GDP) and release $\mathrm{Pi}$ (Fig. 2A). It showed a high preference for ATP with a hydrolysis activity of $0.44 \pm 0.04 \mu \mathrm{mol} / \mathrm{L} \cdot \mathrm{min}^{-1}$ $\mathrm{Pi} / \mu \mathrm{mol} / \mathrm{L}$ protein, which was 3 -fold higher than that obtained with GTP. In the presence of ADP and GDP, however, low hydrolysis activities have been detected. The preferred order of MamK nucleotide hydrolysis activity was ATP > GTP $>$ ADP (or GDP), suggesting that MamK preferentially hydrolyzes NTP over NDP.

The substrates and products of nucleotide hydrolysis were separated and quantified through high-performance liquid chromatography (HPLC) (Fig. 2B). In the presence of ATP or GTP, MamK could break phosphate bonds and generate ADP or GDP, respectively. These results demonstrate that the MamK protein converts ATP to ADP and GTP to GDP at rates of $0.414 \pm 0.003$ and $0.142 \pm 0.002$ $\mu \mathrm{mol} / \mathrm{L} \cdot \mathrm{min}^{-1} \mathrm{Pi} / \mu \mathrm{mol} / \mathrm{L}$ protein, respectively, consistent with the results of phosphate release assay shown in Fig. 2A. Trace AMP was produced through the additional hydrolysis of ADP $\left(0.059 \pm 0.006 \mu \mathrm{mol} / \mathrm{L} \cdot \mathrm{min}^{-1} \mathrm{Pi} / \mu \mathrm{mol} / \mathrm{L}\right.$ protein $)$ by MamK protein (Fig. 2C). Similar to NTP hydrolysis, ADP and GDP were hydrolyzed by MamK and converted to AMP and GMP, respectively (Fig. 2B). The hydrolysis rates of ADP and GDP were calculated as $0.098 \pm 0.011$ and $0.047 \pm$ $0.002 \mu \mathrm{mol} / \mathrm{L} \cdot \mathrm{min}^{-1} \mathrm{Pi} / \mu \mathrm{mol} / \mathrm{L}$ protein, respectively (Fig. $2 \mathrm{~A}$ and $2 \mathrm{C}$ ). As observed by HPLC, GMP was produced by GDP hydrolysis in the absence of MamK. However, the hydrolysis velocity of GDP in the absence of MamK was approximately $0.04 \mu \mathrm{mol} / \mathrm{L} \cdot \mathrm{min}^{-1}$ of $\mathrm{Pi}$, significantly lower than $0.27 \mu \mathrm{mol} / L \cdot \mathrm{min}^{-1}$ of $\mathrm{Pi}$ in the presence of MamK. 

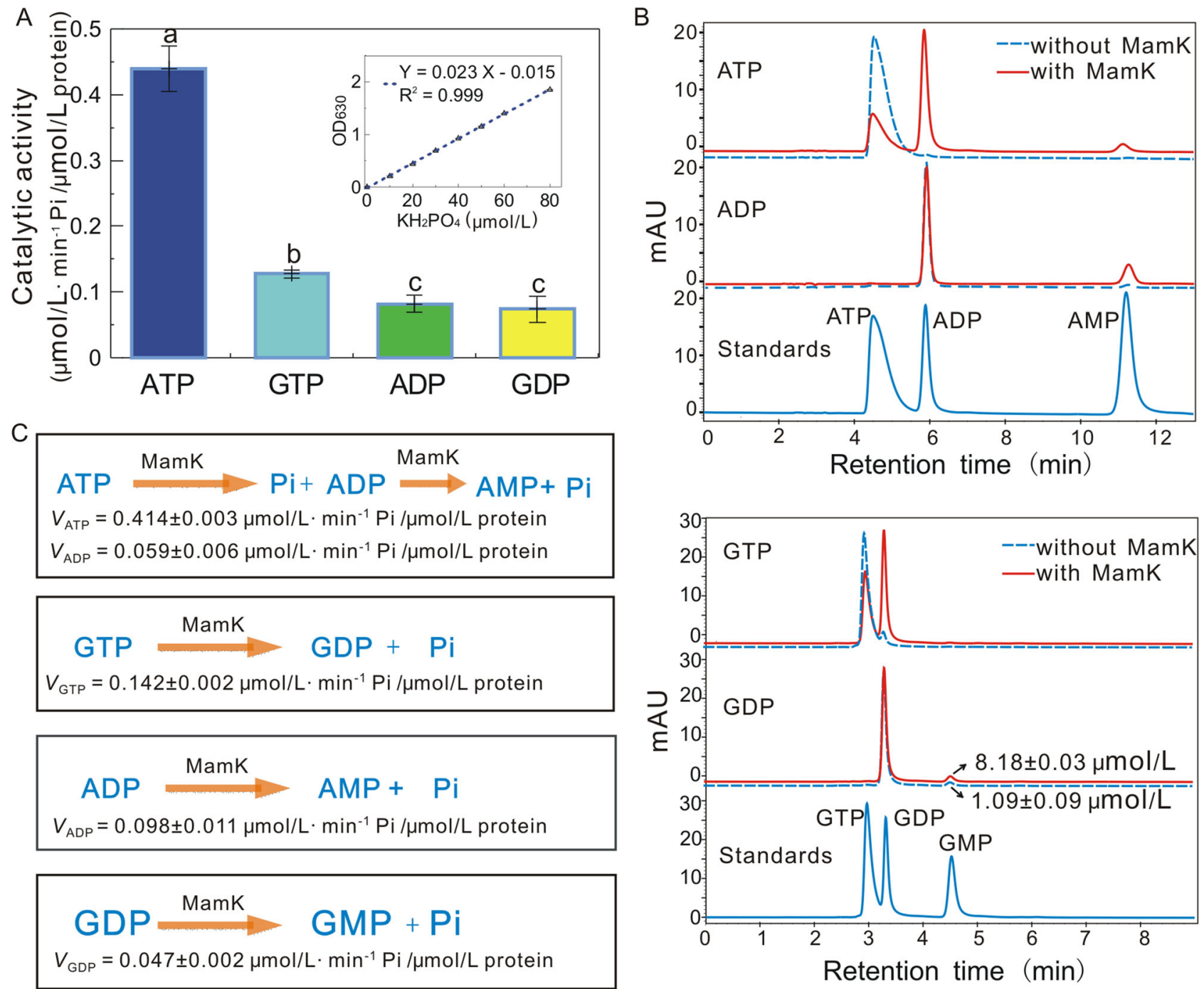

Figure 2. Catalytic efficiencies and reaction processes of MamK towards various nucleotide states. (A) Various NTPase and NDPase activities were assayed based on phosphate release. The inset shows the $\mathrm{KH}_{2} \mathrm{PO}_{4}$ standard curve from 0 to $80 \mu \mathrm{mol} / \mathrm{L}$. MamK hydrolyzed ATP, GTP, ADP and GDP and showed the highest catalytic activity towards ATP. Results are given as the mean $\pm \mathrm{SD}(n=3)$. Different letters indicate significant differences among various nucleotide substrates (Duncan's multiple range test, $P<0.05$ ). (B) HPLC detection of the products formed from the hydrolysis of different nucleotide substrates by MamK. As a negative control, the reaction mixture was incubated under identical conditions, but in the absence of the MamK protein. ATP, ADP AMP, GTP, GDP and GMP were used as standards. (C) Catalytic reaction of MamK NTPases and NDPases. MamK catalyzed the formation of NDP and NMP from NTP and NDP, respectively.

\section{Biochemical properties of MamK ATPase activity}

The effects of temperature, $\mathrm{pH}$, divalent metal ions and salts on the ATPase activity of MamK have been investigated (Fig. 3). MamK could retain more than $80 \%$ activity at temperatures ranging from 35 to $55^{\circ} \mathrm{C}$ and a pH ranging from 7.0 to 9.5 , with maximum enzyme activity observed at $50^{\circ} \mathrm{C}$ and $\mathrm{pH}$ 9.0, (Fig. 3A and 3B). To determine the tolerant ability of MamK protein towards high temperatures, the thermal stability was evaluated by its residual ATPase activity after incubation of MamK at temperatures ranging from $30^{\circ} \mathrm{C}$ to $70^{\circ} \mathrm{C}$ for $30 \mathrm{~min}$. As shown in Fig. 3A, MamK retained appropriately
$100 \%$ activities at the temperatures of $30^{\circ} \mathrm{C}-40^{\circ} \mathrm{C}$, but the residual activity started to decrease at $50^{\circ} \mathrm{C}$ and could not be detected at $60^{\circ} \mathrm{C}$, indicating that MamK protein was stable up to $40^{\circ} \mathrm{C}$ and started to denature around $50^{\circ} \mathrm{C}$.

Among the various divalent metal ions and salt concentrations ranging from 0 to $500 \mathrm{mmol} / \mathrm{L}, 0.1-1.0 \mathrm{mmol} / \mathrm{L}$ of $\mathrm{Mg}^{2+}$ could activate MamK with maximum activity at $0.2 \mathrm{mmol} / \mathrm{L}$, whereas inhibitory effects were observed at concentrations above $2.0 \mathrm{mmol} / \mathrm{L}$ (Fig. 3C). Nearly no effects on the enzyme's activity were observed for $\mathrm{Fe}^{2+}$ or $\mathrm{Ni}^{2+}$ at concentrations of $0-2.0 \mathrm{mmol} / \mathrm{L}$; however, inhibitory effects 
A

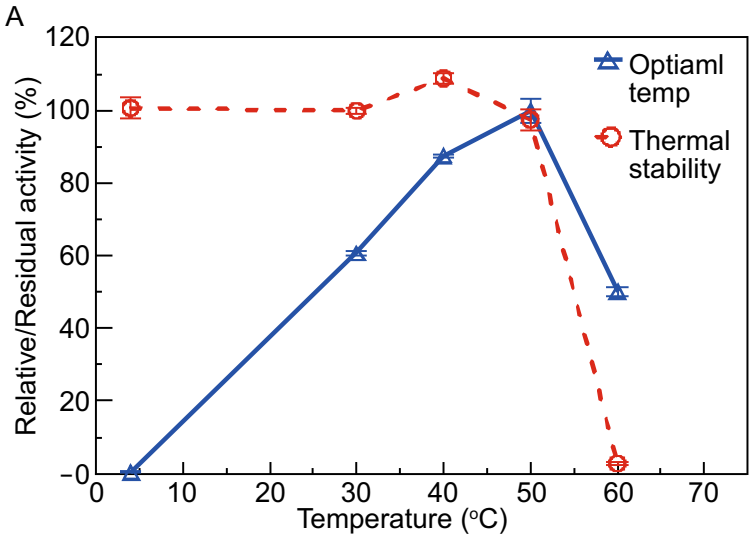

C

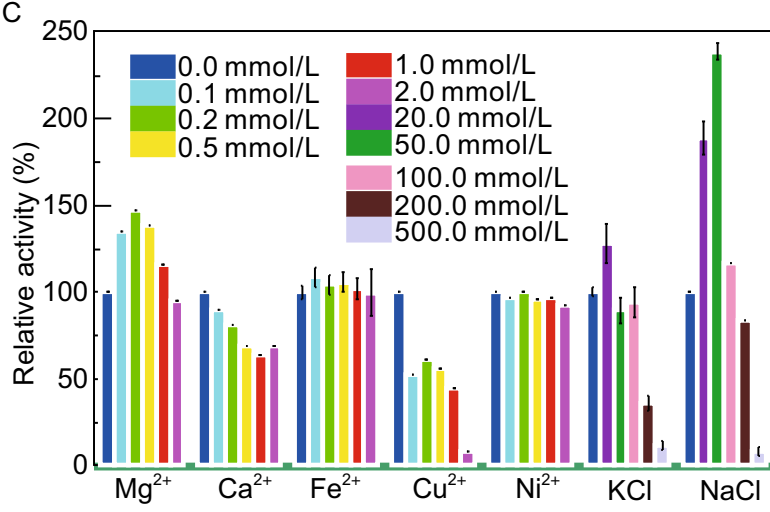

B

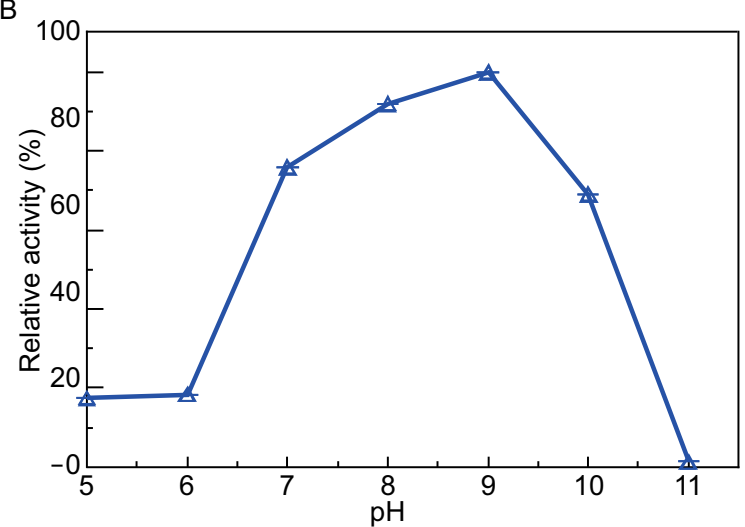

D

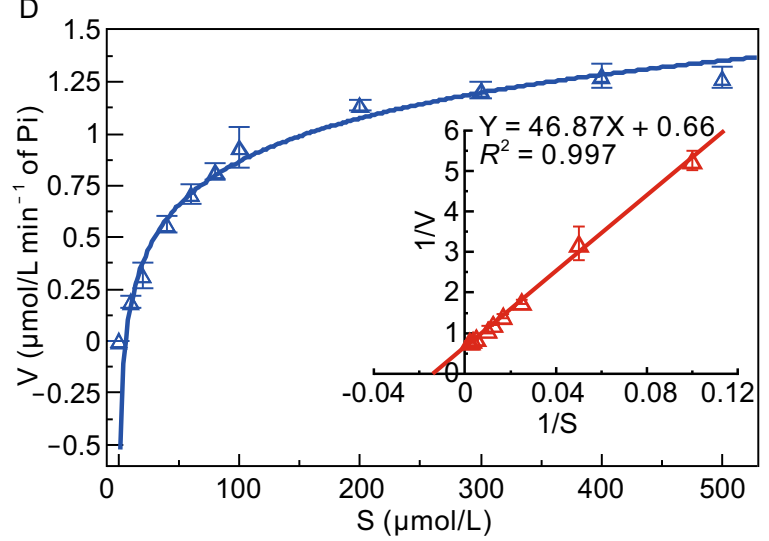

Figure 3. The biochemical properties of MamK ATPase activity. (A) The effect of temperature. The maximum enzyme activity and thermal stability were observed at $50^{\circ} \mathrm{C}$ and $40^{\circ} \mathrm{C}$, respectively. (B) The effect of $\mathrm{pH}$. More than $80 \%$ of MamK enzyme activity was retained within a $\mathrm{pH}$ range of 7.0-9.5, with maximum activity observed at $\mathrm{pH} 9.0$. (C) The effects of various divalent cations and salts. Concentrations ranging from 0.1 to $1.0 \mathrm{mmol} / \mathrm{L} \mathrm{Mg}^{2+}$ and from 20 to $100 \mathrm{mmol} / \mathrm{L} \mathrm{NaCl}$ significantly affected MamK ATPase activity. (D) The kinetic parameters assayed under different concentrations of ATP. The Michaelis constants Vmax and Km for the enzyme reaction were determined as the reciprocal of the absolute $x$-intercept and $y$-intercept, respectively, after plotting the reciprocal of the catalytic efficiency $(1 / \mathrm{V})$ versus the reciprocal of the substrate concentration $(1 / \mathrm{S})$.

were observed for $\mathrm{Ca}^{2+}$ and $\mathrm{Cu}^{2+}$ at each concentration tested. The enzyme activity was slightly activated by $20 \mathrm{mmol} / \mathrm{L} \mathrm{KCl}$, but inhibition of enzyme activity increased with increasing salt concentrations. $\mathrm{NaCl}$ concentrations ranging from $20-100 \mathrm{mmol} / \mathrm{L}$ had a significant stimulatory effect on ATPase activity with a maximum relative activity of approximately $238.9 \%$ in the presence of $50 \mathrm{mmol} / \mathrm{L} \mathrm{NaCl}$ (Fig. 3C). Therefore, $\mathrm{Mg}^{2+}$ and $\mathrm{NaCl}$ played roles in the activation of MamK ATPase activity. The optimal conditions for the ATPase activity of MamK were $0.2-1.0 \mathrm{mmol} / \mathrm{L} \mathrm{Mg}^{2+}$, 20-100 mmol/L NaCl/20 mmol/L KCl, pH 7.0-9.0 and $35^{\circ} \mathrm{C}-50^{\circ} \mathrm{C}$. The biochemical properties of MamK ATPase activity could provide a reference for investigating the physicochemical conditions of its polymerization.

The enzyme kinetic parameters were determined to further define the unique characteristics of the ATPase activity of MamK. Based on the plot shown in Fig. 3D, we calculated the
$V m a x$ and $\mathrm{Km}$ of the ATPase activity as $1.52 \mu \mathrm{mol} / \mathrm{L} \cdot \mathrm{min}^{-1}$ $\mathrm{Pi} / \mu \mathrm{mol} / \mathrm{L}$ protein and $71.02 \mu \mathrm{mol} / \mathrm{L}$, respectively. The catalytic constant (Kcat) and efficiency $(K c a t / K m)$ were calculated as $3.8 \mathrm{~min}^{-1}$ and $0.08 \mathrm{~min}^{-1} \cdot \mu \mathrm{mol} / \mathrm{L}^{-1}$, respectively.

\section{MamK assembles into well-ordered filaments in an ATP-dependent manner}

Among the various parameters affecting bacterial actin polymerization, nucleotide substrates were crucial for the assembly of MamK into filaments. A pelleting assay was performed to determine the distribution of MamK between the monomeric and polymeric states after the MamK was purified (Fig. S1). The formation and structure of filaments in vitro were confirmed through transmission electron microscopy (TEM). In the absence of nucleotides, MamK proteins primarily remained in the soluble fraction and no 
filament formation was observed (Figs. 4A and S2A). Similar results were observed after the addition of GTP (Fig. 4A). In contrast, most of proteins were detected in pellet fraction in the presence of ATP. Moreover, the addition of nonhydrolyzable ATP analogues ATP-Y-S and AMP-PNP resulted in a smaller proportion of protein in the pellet fraction relative to the supernatant (Fig. 4A). However, filaments assembled with ATP- $y-S$ were loose and irregularly shaped, whereas filaments formed with AMP-PNP were shorter than those with ATP (Fig. S2C and S2D). When MamK assembled with ATP, well-ordered filaments with long and straight bundles comprising multiple filaments were observed. These welldeveloped filamentous bundles were greater than $3.5 \mu \mathrm{m}$ in length and $30 \mathrm{~nm}$ in width (Fig. $4 \mathrm{~B}$ and $4 \mathrm{C}$ ). These bundles with average diameters of $32.3 \pm 1.6 \mathrm{~nm}$ were highly ordered through multiple filaments with widths of approximately $6.1 \pm 0.3 \mathrm{~nm}$ (Fig. 4D-H), which is different from the twisted filaments observed in the Magnetospirillum MamK bundles (Sonkaria et al., 2012; Taoka et al., 2007). These results indicate that Mcas MamK could polymerize into long, straight, well-ordered filaments in vitro in an ATP-dependent manner.

His-tags could affect the assembly behaviours of MamK and MreB homologs (Ozyamak et al., 2013b; Esue et al., 2005). In the present study, MamK with a poly-histidine tag at the $\mathrm{C}$ - or $\mathrm{N}$-terminus was examined (Fig. S3). Compared to the well-ordered filamentous bundles polymerized by the MamK with three residues at the $\mathrm{N}$-terminus after the polyhistidine tag being removed, his-tagged MamK formed shorter and irregular filaments under the same polymerization conditions (Fig. S3B and S3C). Therefore, his tags could influence the formation of Mcas MamK filamentous structures, likely through alterations in MamK polymerization.

\section{MamK polymer formation under unique physicochemical conditions}

To further characterize the parameters affecting the ATPase activity of MamK, we have analyzed the effects of different physicochemical conditions (temperature, divalent cations and salts) on MamK polymerization. At temperatures ranging from $20^{\circ} \mathrm{C}-50^{\circ} \mathrm{C}$, MamK assembled into regular filaments with the highest efficiency and the best-ordered structures observed at $37^{\circ} \mathrm{C}$. MamK proteins denatured at temperatures above $50^{\circ} \mathrm{C}$ (Fig. S4). In the absence of metal ions, MamK proteins could assemble into well-ordered filaments with ATP, similar to the products obtained in the presence of both ATP and $\mathrm{Mg}^{2+} . \mathrm{Mg}^{2+}$ slightly increased the amount of filaments, suggesting that the polymerization rate of MamK could be improved by $\mathrm{Mg}^{2+}$ (Fig. S5A). Furthermore, the pelleting assay revealed that more filaments were formed in the presence of $\mathrm{Ca}^{2+}$ compared to $\mathrm{Mg}^{2+}$. However, in the presence of $\mathrm{Ca}^{2+}$ single disordered and irregularly shaped filaments were formed that lacked obvious bundles (Fig. S5E). These results suggest that the polymerization of MamK is independent of metal ions, but could be stimulated by $\mathrm{Mg}^{2+}$ and $\mathrm{Ca}^{2+}$. The filaments formed in the absence of metal ions or in the presence of $\mathrm{Mg}^{2+}$ were well ordered, whereas in the presence of $\mathrm{Ca}^{2+}$, the polymers were irregular.

Because $\mathrm{KCl}$ and $\mathrm{NaCl}$ are important in bacterial actin assembly, the effects of these cations on MamK assembly were also investigated (Fig. 5). The polymerization efficiency was slightly improved by increasing concentrations of $\mathrm{KCl}$ from $20-200 \mathrm{mmol} / \mathrm{L}$; however, the efficiency decreased with increasing $\mathrm{NaCl}$ concentrations (Fig. 5A). The effects of salts on MamK assembly were different from the effects of those on ATPase activity (Fig. 3C). The filaments formed in the presence of different salt concentrations were further investigated through TEM. In the presence of $0-20 \mathrm{mmol} / \mathrm{L}$ $\mathrm{KCl}$ or $\mathrm{NaCl}$, only single filaments were observed (Fig. 5B-D). The structures of filaments formed with $\mathrm{NaCl}$ were better organized than those formed with $\mathrm{KCl}$. When the salt concentration was increased to $50 \mathrm{mmol} / \mathrm{L}$, the filaments preferentially clustered to form multiple bundles. An increase in $\mathrm{KCl}$ or $\mathrm{NaCl}$ from $50-200 \mathrm{mmol} / \mathrm{L}$ induced the formation of multiple filament bundles, suggesting that the bundling of MamK filaments was dependent on the ionic strength of buffer.

\section{MamK polymerization kinetics}

The individual filaments of Alexa 488-labelled MamK polymerized in ATP were traced and imaged using time-lapse microscopy. We could not detect any growing filaments in any of the nucleotide substrates other than ATP. The filament structures formed by $0-8.57 \mu \mathrm{mol} / \mathrm{L}$ of labelled MamK were confirmed by TEM (Fig. S6). The detailed processes of MamK filament assembly in the presence of ATP were shown in Fig. S7. The polymerization kinetics of MamK filaments labelled with Alexa 488 was examined using increasing protein concentrations in saturating amounts of ATP. The polymerization rate initially increased in a protein concentration-dependent manner (Fig. 6A). The assembly kinetics was consistent with a cooperative polymerization mechanism comprised of two apparent phases: an initial increase in polymer formation followed by a slow approach to steady state. A long lag phase was reached during protein polymerization at $1.07 \mu \mathrm{mol} / \mathrm{L}$. Polymer formation below $1.0 \mu \mathrm{mol} / \mathrm{L}$ of MamK protein could not be detected by fluorescence microscopy. The critical concentration of filament assembly in the presence of $\mathrm{Mg}^{2+}$-ATP and $\mathrm{NaCl}$ was calculated as $1.0 \mu \mathrm{mol} / \mathrm{L}$ (Fig. $6 \mathrm{~B}$ ), a value greater than that observed for MamK from AMB-1 ( 0.7 $\mu \mathrm{mol} / \mathrm{L}$ ) (Ozyamak et al., 2013b) but less than that for MamK from MSR-1 $(1.4 \mu \mathrm{mol} / \mathrm{L})$ (Sonkaria et al., 2012). A plot of the logarithm of maximum polymerization rate versus the logarithm of protein concentration revealed that the nucleus size of MamK filament was trimeric in $\mathrm{Mg}^{2+}$-ATP and $\mathrm{NaCl}$ (Fig. 6C). The rate constant of nucleation reaction was 5.04, reflecting a rapid nucleation rate similar to ParM ( 4.82-4.84) (Garner et al., 2004; Rivera et al., 2011). 
A

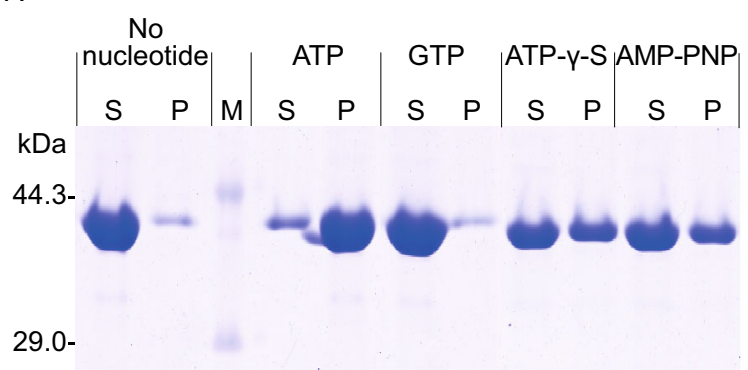

C

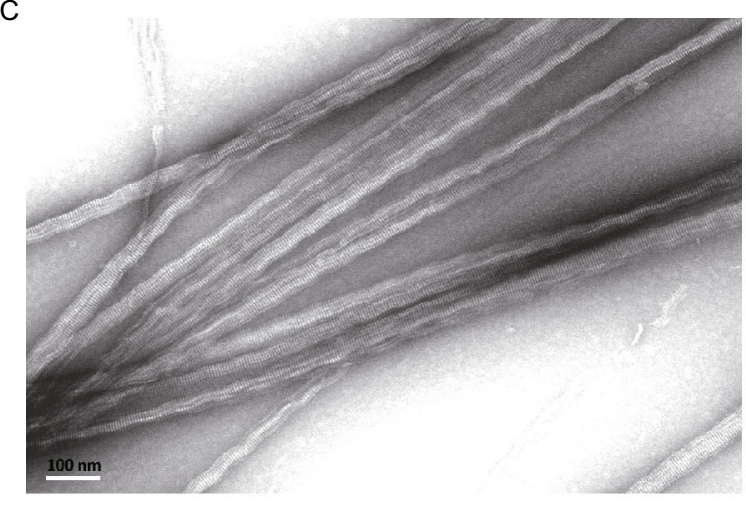

E
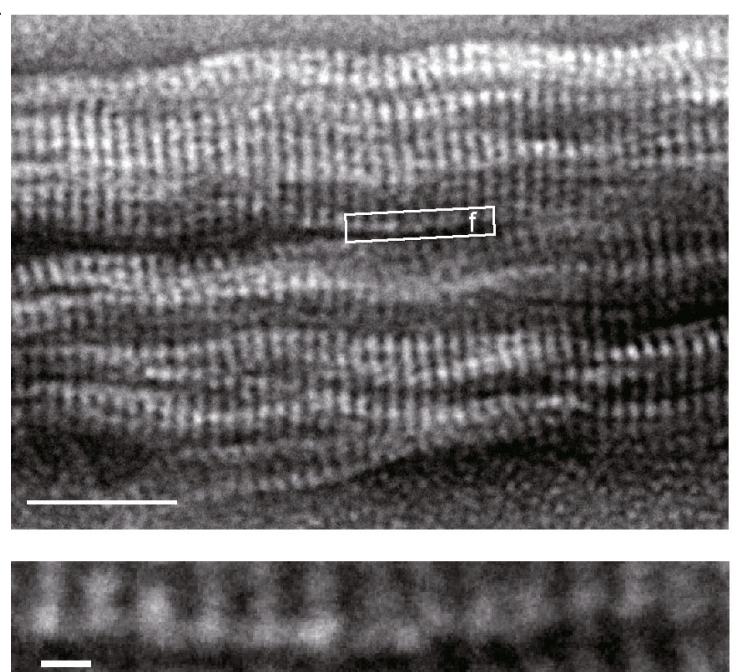

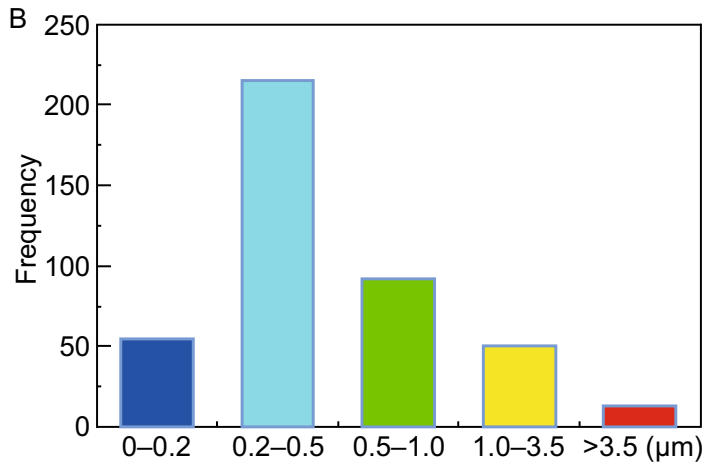

D

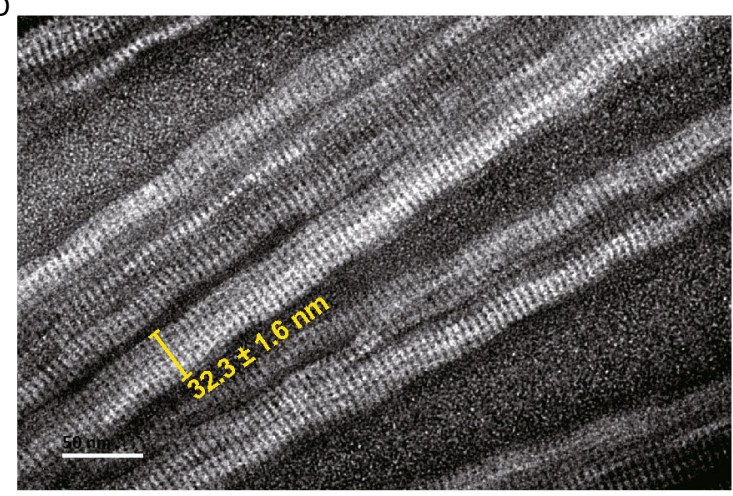

G

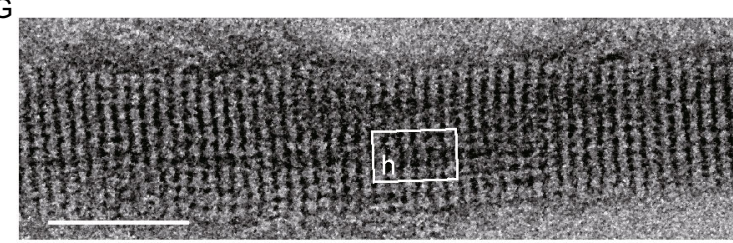

$\mathrm{H}$

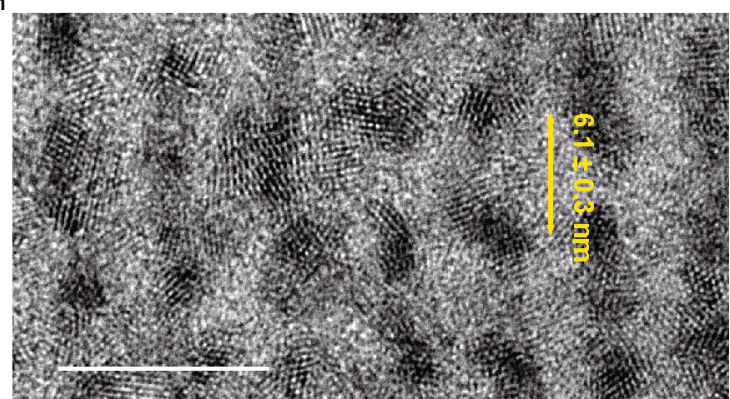

Figure 4. MamK filaments formed in the presence of ATP. (A) MamK polymerization in the presence of various nucleotide states was assessed by a pelleting assay. The supernatant $(S)$ and pellet $(P)$ fractions were analyzed by SDS-PAGE. In the presence of ATP, ATP- $Y$-S or AMP-PNP, the proportion of the pellet in the total protein was clearly increased compared to the negative control without any nucleotide. (B) The distribution of the filamentous lengths formed in the presence of ATP, $\mathrm{Mg}^{2+}$ and $\mathrm{NaCl}$. The majority of MamK filaments ranged from 0.2 to $0.5 \mu \mathrm{m}$ in length, and the well-developed filaments were more than $3.5 \mu \mathrm{m}$ in length. $(\mathrm{C}-\mathrm{H})$ Negatively stained MamK polymers visualized by TEM. In vitro, MamK polymerized into well-ordered filaments comprised of multiple filaments in an ATP-dependent manner. Panel C scale bars, $100 \mathrm{~nm}$; panel D scale bar, $50 \mathrm{~nm}$; panel E scale bar, $50 \mathrm{~nm}$; panel F scale bar, $5 \mathrm{~nm}$; panel $\mathrm{G}$ scale bar, $50 \mathrm{~nm}$; and panel $\mathrm{H}$ scale bar, $10 \mathrm{~nm}$.

As shown in Fig. 6D, ATP hydrolysis through MamK lagged behind ATP polymerization, except during the initial reaction period $(0-60 \mathrm{~s})$, in which they appeared to be concomitant. In the initial nucleation phase, there was rapid formation of nucleotide triphosphate-bound MamK monomers, which had undergone rapid hydrolysis, for the nucleus 

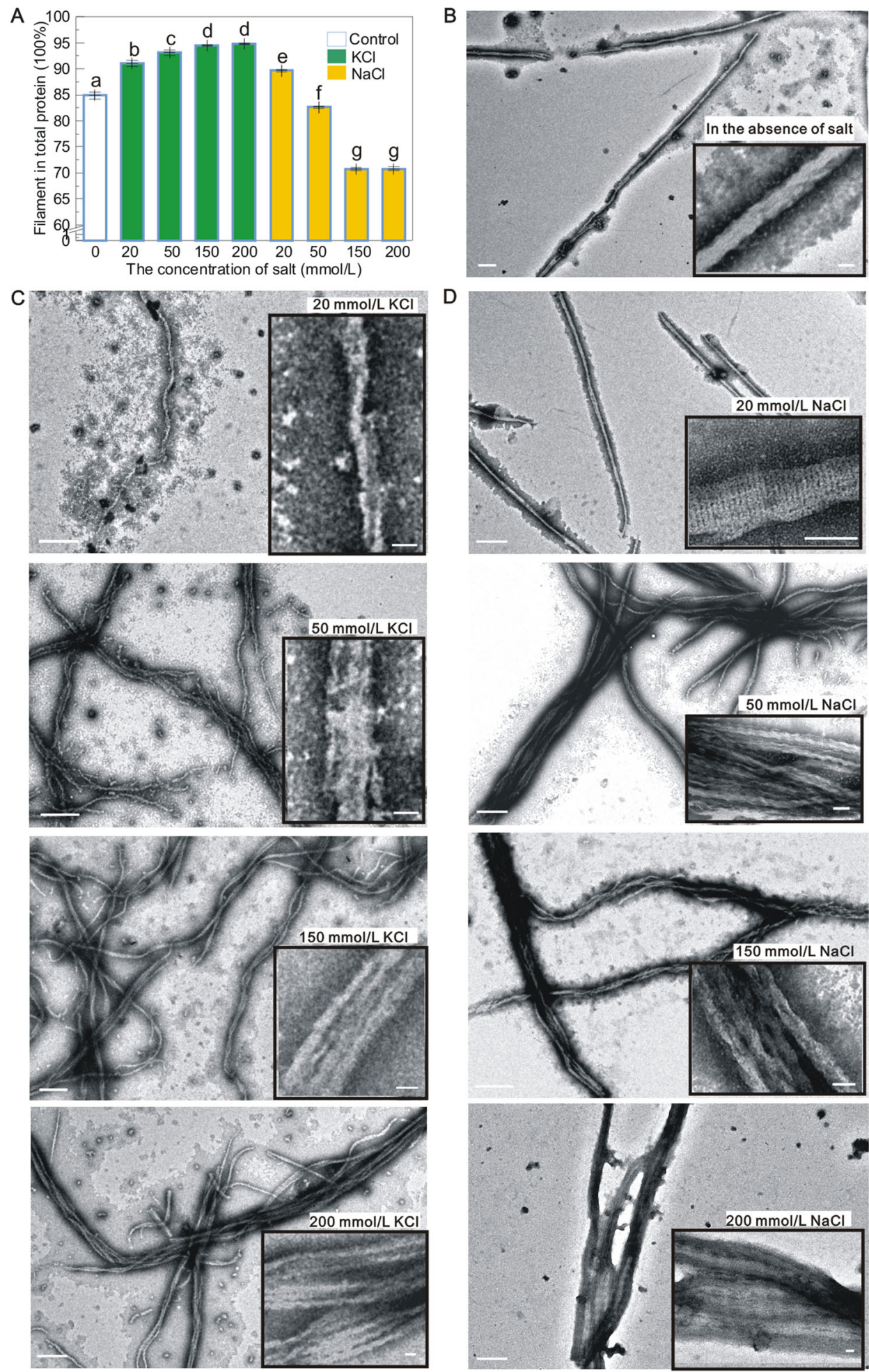

establishment. Subsequently, the ATP hydrolysis rate decreased sharply and a constant relative rate of phosphate production $\left(3.2 \pm 0.2 \mu \mathrm{mol} / \mathrm{L} \cdot \mathrm{min}^{-1}\right.$ of $\left.\mathrm{Pi}\right)$ was observed at both increasing and steady states of polymerization. Therefore, it is reasonable to speculate that ATP hydrolysis is

triggered through MamK polymerization and might play an essential role in filament turnover. According to the results of the present study, a model for the filament assembly of MamK in genus ' $\mathrm{Ca}$. magnetobacterium' could be proposed (Fig. S8). 
4 Figure 5. MamK polymers assembled into bundles in a salt-dependent manner. (A) The efficiency of MamK filament polymerization in different salt concentrations. The percent ratio of MamK filaments in the total protein represents the polymerization efficiency. Results are given as the mean $\pm \operatorname{SD}(n=4)$. Different letters indicate significant differences among the various concentrations of salt (Duncan's multiple range test, $P<0.05$ ). (B) Single MamK filaments were observed in the absence of salt. ( $C$ and $\mathrm{D}$ ) MamK filaments formed in $\mathrm{KCl}$ and $\mathrm{NaCl}$ at concentrations ranging from 20 to $200 \mathrm{mmol} / \mathrm{L}$. The formation of single filaments was observed in the presence of $20 \mathrm{mmol} / \mathrm{L} \mathrm{KCl}$ or $\mathrm{NaCl}$, and filaments with a well-ordered structure were observed with $\mathrm{NaCl}$. MamK filaments preferentially clustered to form bundles in the presence of increasing $\mathrm{KCl}$ or $\mathrm{NaCl}$ concentrations ranging from 50 to $200 \mathrm{mmol} / \mathrm{L}$. The insets show high magnification images. The $500 \mathrm{~nm}$ and $50 \mathrm{~nm}$ scale bars are shown in the low and high magnification images, respectively.

\section{DISCUSSION}

Bacterial actin protein MamK plays an essential role in the linear chain arrangement of intracellular magnetite or greigite magnetosomes in MTB, which are a model system for investigating organelle biogenesis in prokaryotes (Schüler, 2008; Cornejo et al., 2014). In the present study, we have characterized the in vitro biochemical functions, structural features and assembly behaviours of MamK from Mcas, an uncultivated Nitrospirae MTB that forms multiple bundles of bullet-shaped magnetite magnetosome chains.

The hydrolysis of nucleotide phosphate is a common property of functionally diverse bacterial actin proteins. Although some bacterial actin proteins produce inorganic phosphates only in the presence of tri-phosphate nucleotides (Sonkaria et al., 2012; Mayer and Amann, 2009), MamK protein from Mcas produces phosphates not only in the presence of ATP and GTP but also with ADP and GDP (Fig. 2). In MSR-1, the levels of ATPase and GTPase activities for MamK were similar (Sonkaria et al., 2012); however, MamK from Mcas displayed a high ATPase activity $\left(0.44 \pm 0.04 \mu \mathrm{mol} / \mathrm{L} \cdot \mathrm{min}^{-1} \mathrm{Pi} / \mu \mathrm{mol} / \mathrm{L}\right.$ protein $)$ that was threefold higher than the GTPase activity. The ATPase activity of MamK from Mcas was higher than that from AMB-1 (Ozyamak et al., 2013b) but lower than that of ParM (approximately 3-6 $\mu \mathrm{mol} / \mathrm{L} \cdot \mathrm{min}^{-1} \mathrm{Pi} / \mu \mathrm{mol} / \mathrm{L}$ protein) (Garner et al., 2004; Rivera et al., 2011). Although Mcas MamK could bind and hydrolyze ADP and GDP, the catalytic activities towards both substrates were significantly lower than that towards ATP or GTP, with ATP as the most preferred substrate. We have developed an HPLC assay to further determine the hydrolysis of various nucleotides. The transitions of various NTPase and NDPase catalytic reactions between substrates and products were precisely determined, from which the MamK protein could convert NTP to NDP and NDP to NMP, respectively.

Previous studies have demonstrated the transitions of bacterial actins between monomeric and filamentous states
(Ozyamak et al., 2013a). For instance, MamK proteins from MS-1 and MSR-1 polymerize into filaments in vitro with a nonhydrolyzable ATP analogue (ATP-y-S) as the optimal substrate (Sonkaria et al., 2012; Taoka et al., 2007). In contrast, AMB-1 MamK with a His tag polymerized in the absence of nucleotides (Rioux et al., 2010), but untagged proteins efficiently assembled into filaments in the presence of ATP (Ozyamak et al., 2013b). Because the MamK proteins investigated in previous studies were more than $94 \%$ identical, the his tags used in different studies could alter the assembly behaviours of MamK proteins (Ozyamak et al., 2013b). Although Mcas MamK has a relatively low identity $(\sim 40 \%)$ to Magnetospirillum MamK, TEM observations showed that tags could significantly affect Mcas MamK filamentous structures (Fig. S3). Different assembly properties have also been observed for untagged and his-tagged MreB from T. maritima (Bean and Amann, 2008). Additionally, despite the broad hydrolysis of various nucleotides, Mcas MamK only assembled well in the presence of ATP. No filament was detected with GTP, and only irregularly shaped filaments were formed with nonhydrolyzable ATP analogues (ATP-Y-S or AMP-PNP) (Fig. S2). However, many bacterial actins, including ParM (Rivera et al., 2011), MreB (Mayer and Amann, 2009; Ent et al., 2001) and AlfA (Popp et al., 2010), could polymerize with ATP, GTP or analogues. Indeed, recent studies have revealed that AMB-1 MamK polymerizes in the presence of ATP and GTP at different critical concentrations (Ozyamak et al., 2013b). However, the efficient polymerization of regular Mcas MamK filaments was only triggered through ATP in vitro.

Certain physicochemical parameters including divalent cations and salts are important factors for bacterial actin protein assembly. Although the polymerization of AMB-1 (Ozyamak et al., 2013b) and MSR-1 (Sonkaria et al., 2012) MamK proteins requires $\mathrm{Mg}^{2+}$, this divalent cation was not strictly required for the assembly of Mcas MamK, though its polymerization rate was slightly enhanced by $\mathrm{Mg}^{2+}$. Previous studies have also suggested that $\mathrm{Mg}^{2+}$ was not necessary for the assembly of TmMreB, and the inhibitory effect of this cation on TmMreB was in contrast to that on MamK proteins (Esue et al., 2005; Ent et al., 2001). Sonkaria et al. monitored the light scattering intensity and revealed that $1 \mathrm{mmol} / \mathrm{L}$ of $\mathrm{Ca}^{2+}$ could maximize the polymerization efficiency of MSR-1 MamK (Sonkaria et al., 2012). A similar result was also observed in the present study, but the filamentous structure of Mcas MamK was irregular (Fig. S5). These results suggest that using light scattering intensity and pelleting assays to score bacterial actin polymerization should be cautious and needs to be further confirmed by transmission electron microscope observations.

Notably, salt concentrations strongly influence MamK polymerization. Sonkaria et al. reported that MamK from MSR-1 effectively polymerized in the presence of $\mathrm{KCl}$ at concentrations from $0-20 \mathrm{mmol} / \mathrm{L}$, whereas polymerization was inhibited by increasing salt concentrations and the polymerization rate was drastically reduced by $200 \mathrm{mmol} / \mathrm{L}$ 
A

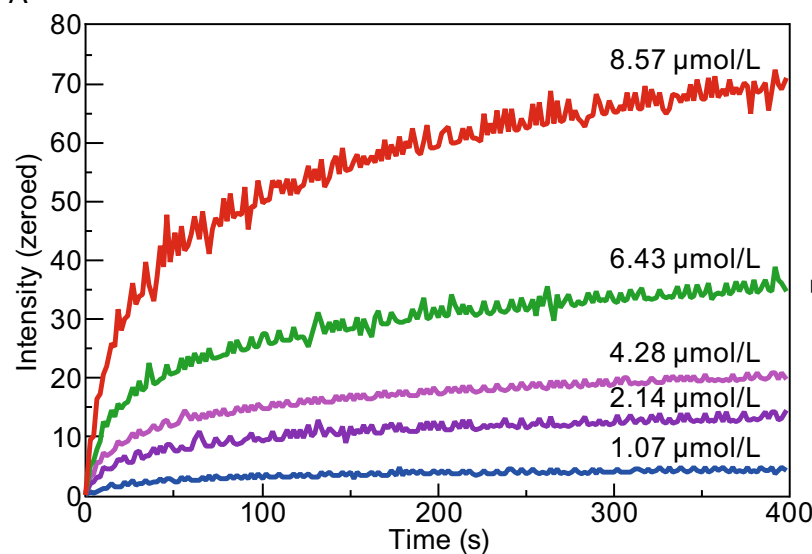

C

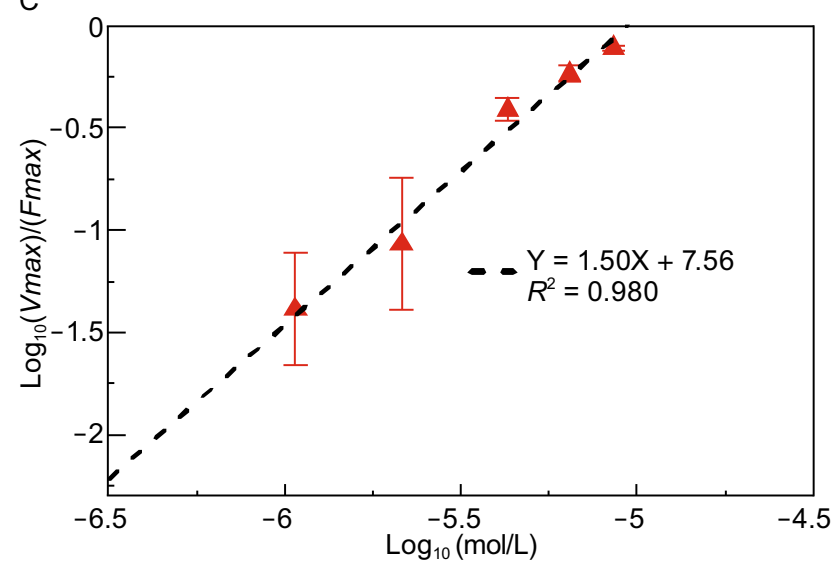

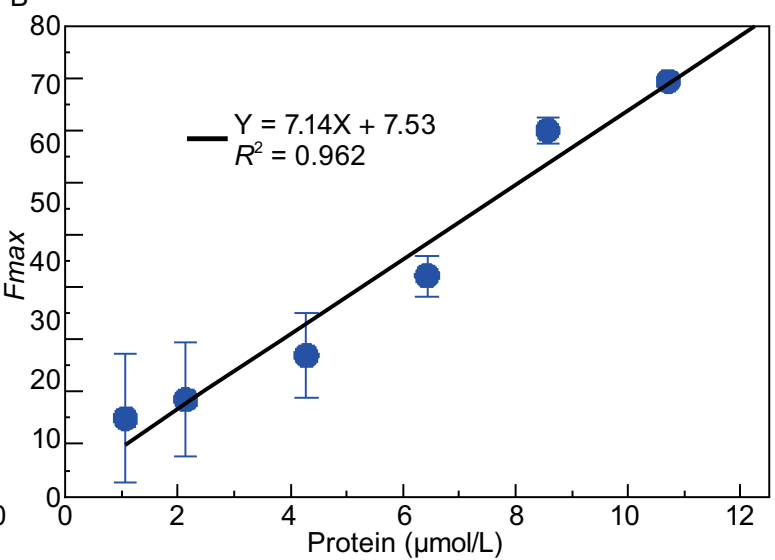

$\mathrm{D}$

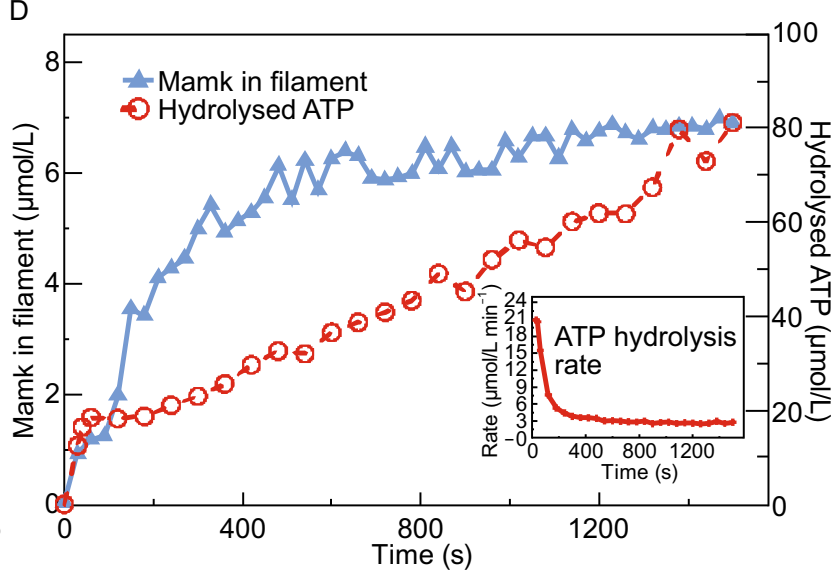

Figure 6. Polymerization kinetics of MamK. (A) Assembly kinetics of MamK at varying concentrations under standard conditions. (B) Determination of the critical concentration, which was determined as the x-intercept after plotting the maximum intensity values versus the protein concentration in (A). (C) Determination of the nucleus size and relative nucleation rates. The logarithm of the maximum polymerization rate is plotted versus the logarithm of the protein concentration in (A). The nucleus size $(n)$ was estimated as two times the slope of the linear fit. The relative nucleation rate $(K n)$ was determined as the $x$-intercept in the plot. (D) Steady ATP hydrolysis during MamK polymerization. MamK in the filaments was determined as the total protein concentration minus the monomer concentration by the Bradford method after the monomers and filaments were separated. ATP hydrolysis was measured as the amount of phosphate released at various time points, and the inset shows the ATP hydrolysis rate $\left(\mu \mathrm{mol} / \mathrm{L} \cdot \mathrm{min}^{-1}\right.$ of $\left.\mathrm{Pi}\right) \mathrm{defined}$ as the amount of released phosphate per minute.

$\mathrm{KCl}$ (Sonkaria et al., 2012). In contrast, MamK from AMB-1 polymerized at high concentrations of $\mathrm{KCl}$, and efficient assembly into bundles was observed at $150 \mathrm{mmol} / \mathrm{L} \mathrm{KCl}$ (Ozyamak et al., 2013b). This KCl-dependent bundling was observed for Mcas MamK in this study. However, the bundling was initiated at $50 \mathrm{mmol} / \mathrm{L} \mathrm{KCl}$ for Mcas MamK filaments, which is higher than that for AMB-1 MamK (Ozyamak et al., 2013b). Similar $\mathrm{NaCl}$-dependent bundling was also observed for Mcas MamK, except that the efficiency of assembly decreased slightly with increasing salt concentrations from $20-200 \mathrm{mmol} / \mathrm{L}$. Altogether, the polymerization conditions for different MamK proteins exhibited a surprising degree of variation for salts. The assembly of bundles might be an intrinsic property of bacterial actin because potassium and sodium are the most abundant cations in bacterial cells.
Thus, this filament bundling at physiological $\mathrm{K}^{+} / \mathrm{Na}^{+}$concentrations in vitro might be related to the static nature of MamK filaments in cells.

Considering the basic physicochemical parameters that define the polymerization of MamK, the assembly kinetics and nucleation mechanisms should be addressed. The molecular mechanism for MamK assembly remains largely unknown because it is difficult to detect assembly events like those of ParM (Garner et al., 2004; Rivera et al., 2011). We investigated the assembly behaviours of MamK filaments using fluorescence microscopy to examine Mcas MamK polymers in vitro. The bulk assembly kinetics of Mcas MamK displayed an initial peak in polymer concentration, followed by a slow approach to equilibrium (Fig. 6). In the initial assembly phase, a large number of dotted polymers formed 
with a high rate of ATPase activity, indicating that the early assembly of MamK proteins might create a burst of hydrolysis equal to the amount of MamK polymerized (Fig. S7). As the dotted polymers started to elongate and associate into bundles, the ATPase activity of MamK reached a plateau because of the limited subunit exchange for dissociation to exchange ADP for ATP and subsequent re-association for hydrolysis. Mcas MamK elongated from a nucleus comprised of three monomers, which is consistent with the nucleus size of AMB-1 MamK and ParM as previously suggested (Garner et al., 2004; Ozyamak et al., 2013b).

The divergent assembly of bacterial actin proteins might reflect the specific adaptation to distinct intracellular physiological functions. For example, the dynamic instability and bidirectional polymerization of ParM could provide the force needed to push plasmids to opposite poles of the cell (Garner et al., 2004; Fusinita et al., 2002). The polymerization of MamK should contribute to organize and maintain magnetosome chain structures. Previous studies have suggested that MamK might interact with methyl-accepting chemotaxis proteins (MCP) at cell poles (Philippe and Wu, 2010). According to our results, it is speculated that MamK monomers in Mcas might bind to ATP, form a three-monomer nucleus and further elongate to form filaments (Fig. S8). Further investigations are needed to fully understand the mechanisms of multiple magnetosome chain assembly in Mcas and their relatives belonging to the Nitrospirae phylum.

In summary, the present study provides evidence for the stable assembly of magnetosome-arranging protein MamK from Mcas that harbours multiple intracellular magnetosome chains. These results provide insights into the biochemical functions, assembly behaviour and filamentous structure of MamK in the poorly understood Nitrospirae phylum.

\section{MATERIALS AND METHODS}

\section{Cloning, expression and purification}

The mamK gene was amplified from Mcas genomic DNA, cloned into the $\mathrm{pET} 28 \mathrm{a}$ and $\mathrm{pET} 22 \mathrm{~b}$ vectors and then expressed in Escherichia coli C43 (DE3) cells (Seignovert et al., 2004). The cells were grown in Luria-Bertani (LB) medium at $37^{\circ} \mathrm{C}$ and induced for $4 \mathrm{~h}$ with $0.5 \mathrm{mmol} / \mathrm{L} \mathrm{IPTG}$ when the $\mathrm{OD}_{600}$ reached 0.8 . Cells were harvested and disrupted through sonication in buffer A containing $20 \mathrm{mmol} / \mathrm{L}$ Tris- $\mathrm{HCl}(\mathrm{pH} 8.0), 150 \mathrm{mmol} / \mathrm{L} \mathrm{NaCl}$ and $10 \%$ glycerol. After centrifugation at $15,000 \times g$ for $30 \mathrm{~min}$, MamK protein in the supernatant was purified through $\mathrm{Ni}^{2+}$ affinity chromatography and gel filtration. The detailed cloning, expression and purification procedures are described in the supplementary information. The purity of the sample was assessed through sodium dodecyl sulfate polyacrylamide gel electrophoresis (SDS-PAGE) (Fig. S1).

\section{Fluorescent labelling of MamK}

For the labelling reactions, purified monomeric MamK was added to a 5-fold molar excess of Alexa-488 dye (Sigma, USA) and incubated at room temperature for $2 \mathrm{~h}$. The reaction was quenched by the addition of $10 \mathrm{mmol} / \mathrm{L}$ DTT after the dye had reacted efficiently with the primary amines of proteins to form stable dye-protein conjugates. The labelled protein was purified through gel filtration on Bio-Rad BioGel P-30 fine size exclusion resin to remove the free dye. The degree of labelling is described in the supplementary information. The proteins labelled with approximately 1 mole of fluorophore per mole of MamK were used in the present study. The samples were divided into small aliquots, light protected and stored at $-20^{\circ} \mathrm{C}$. The ATPase activity and filamentous structure of the labelled proteins were determined to estimate their functions (Fig. S6).

\section{Nucleotide hydrolysis activities assay}

A modified malachite-green method based on spectrophotometry was used to determine the NTPase and NDPase activities (Webb, 1992; Fisher and Higgins, 1994). The nucleotide hydrolysis activity was assayed in buffer B containing $20 \mathrm{mmol} / \mathrm{L}$ Tris- $\mathrm{HCl}(\mathrm{pH} 8.0)$, $0.2 \mathrm{mmol} / \mathrm{L} \mathrm{MgCl}_{2}, 50 \mathrm{mmol} / \mathrm{L} \mathrm{NaCl}$ and $0.2 \mathrm{mmol} / \mathrm{L}$ nucleotide substrate (ATP, GTP, ADP or GDP). The enzyme solution was added to a final concentration of $0.4 \mu \mathrm{mol} / \mathrm{L}$ in the total reaction mixture to determine the release of inorganic phosphate $(\mathrm{Pi})$. The nucleotide hydrolysis reaction containing $2 \mu \mathrm{mol} / \mathrm{L}$ of MamK in buffer $\mathrm{B}$ was performed at $37^{\circ} \mathrm{C}$ for $30 \mathrm{~min}$ and then terminated after the addition of 4 volumes of chromogenic reagent, which was optimized as $0.67 \mathrm{~mol} / \mathrm{L} \mathrm{H}_{2} \mathrm{SO}_{4}, 0.02 \mathrm{~mol} / \mathrm{L}$ ammonium molybdate, $0.63 \%$ Tween 20 and $0.03 \%$ malachite green. The chromogenic reaction was performed at room temperature for $30 \mathrm{~min}$, and the absorbance of the total reaction mixture was subsequently measured at $\mathrm{OD}_{630}$. The reaction mixture in the absence of enzyme treated under the same conditions was used as the control. The enzyme activity was defined as the amount of released phosphate $(\mu \mathrm{mol} / \mathrm{L})$ catalyzed by $1 \mu \mathrm{mol} / \mathrm{L}$ of enzyme per minute under the experimental conditions (Ozyamak et al., 2013b). The absorbance of the reaction mixture at $0 \mathrm{~min}$ and $30 \mathrm{~min}$ was assayed to calculate the released phosphate, which was quantified using a $\mathrm{KH}_{2} \mathrm{PO}_{4}$ standard curve. Based on the malachitegreen assay, the MamK ATPase features were determined as described in the supplementary information. All measurements were performed in at least triplicate.

\section{HPLC assay for nucleotide states}

The substrates and products of the NTPase and NDPase catalytic reactions were assayed by HPLC. After incubation at $37^{\circ} \mathrm{C}$ for $30 \mathrm{~min}$, the assay was terminated upon the addition of $1 \mu \mathrm{L}$ of $100 \%$ trichloroacetic acid (TCA). The samples were filtered through a $0.22-\mu \mathrm{m}$ filter and ran on an Agilent 1200 HPLC equipped with a Zorbax SB-Aq column (4.6 $\times 250 \mathrm{~mm}$; Agilent Technologies, USA). A $0.5 \% \mathrm{KH}_{2} \mathrm{PO}_{4}$ solution ( $\mathrm{pH} 4.5$ ) and methanol were used as mobile phases $\mathrm{A}$ and $\mathrm{C}$, respectively. HPLC was performed at a constant flow rate of $1.0 \mathrm{~mL} / \mathrm{min}$ with $95 \%(\mathrm{v} / \mathrm{v})$ phase $\mathrm{A}$ and $5 \%(\mathrm{v} / \mathrm{v})$ phase C. The UV absorption was measured at $254 \mathrm{~nm}$, and the column temperature was maintained at $25^{\circ} \mathrm{C}$. Various nucleotide states, including ATP, ADP, AMP, GTP, GDP and GMP (Sigma, USA), were used as standards to determine the retention times and amounts of the various ingredients in the reaction mixture. The reaction mixtures assayed using the same procedure in the absence of MamK proteins served as negative controls. Compared with the negative controls, the hydrolysis rate was calculated by the change in the 
concentrations $(\mu \mathrm{mol} / \mathrm{L})$ of the substrates or products catalyzed by $1 \mu \mathrm{mol} / \mathrm{L}$ of enzyme per minute under the experimental conditions.

\section{MamK polymerization and pelleting assays}

Purified MamK was added at a final concentration of $8.5 \mu \mathrm{mol} / \mathrm{L}$ in a total volume of $100 \mu \mathrm{L}$ of polymerization buffer containing $20 \mathrm{mmol} / \mathrm{L}$ Tris- $\mathrm{HCl}(\mathrm{pH} 8.0), 1 \mathrm{mmol} / \mathrm{L} \mathrm{MgCl}_{2}$ and $50 \mathrm{mmol} / \mathrm{L} \mathrm{NaCl}$. A similar polymerization reaction without nucleotides was used as the negative control to exclude the aggregated protein. Various parameters affecting MamK assembly were determined as described in the supplementary information. The mixture was subsequently centrifuged at $500,000 \times g$ for $30 \mathrm{~min}$ to remove the aggregates. To polymerize the protein, ATP or other nucleotide states were added at a final concentration of $1 \mathrm{mmol} / \mathrm{L}$, and the reaction mixture was immediately incubated at $37^{\circ} \mathrm{C}$ for $30 \mathrm{~min}$. Steady state monomers and filaments were separated through centrifugation at 500,000 $\times \mathrm{g}$ for $30 \mathrm{~min}$. The concentration of the protein monomers in the supernatant was rapidly determined using the Bradford method (Bio-Rad Protein Assay Dye Reagent, USA). To evaluate MamK polymerization, the pellets were suspended in $100 \mu \mathrm{L}$ of polymerization buffer, and equal volumes of the supernatant and pellet samples were separated by SDS-PAGE on $5 \%$ stacking and $10 \%$ running gels. The protein bands were visualized by Coomassie Brilliant Blue G250 staining and quantitated using the NIH ImageJ program (http://rsb.info.nih.gov/ij/). The amount of pellets in the total protein was quantitated and verified as the amount of the monomer in the same reaction. MamK protein in the filament was calculated as the amount of pellets in the reaction mixture minus that of the negative control without nucleotide.

\section{Transmission electron microscopy and image analysis}

MamK filaments were generated in the polymerization reaction mixture containing $20 \mathrm{mmol} / \mathrm{L}$ Tris- $\mathrm{HCl}(\mathrm{pH} 8.0), 50 \mathrm{mmol} / \mathrm{L} \mathrm{NaCl}, 1 \mathrm{mmol} /$ $\mathrm{L} \mathrm{MgCl}_{2}, 8.5 \mu \mathrm{mol} / \mathrm{L}$ of protein and $1 \mathrm{mmol} / \mathrm{L}$ ATP. The mixtures were incubated at $37^{\circ} \mathrm{C}$ for $30 \mathrm{~min}$ and loaded onto carbon-coated grids for $5 \mathrm{~min}$. The grids were washed twice with deionized water, followed by negative staining with $1 \%$ uranyl acetate for $1 \mathrm{~min}$. The products on the grids were observed using a JEM-1400 transmission electron microscope (TEM) operating at $80 \mathrm{kV}$ (JEOL Corporation, Japan). Images were captured by a Gatan 832 CCD camera $(4,008 \times 2,672$ pixels). Protein samples incubated under the same polymerization conditions without substrate were used to confirm the absence of filamentous structures in the purified protein and the polymerization mixture without nucleotide substrate. Filament lengths of more than 400 polymers were analyzed using the NIH ImageJ program.

Polymerization kinetics, critical concentration and phosphate release

Filament assembly was conducted using a fluorescence-based assay as described previously (Garner et al., 2004; Sahoo et al., 2006; Fujiwara et al., 2007). To prepare the polymerization samples, unlabelled protein was doped with $15 \%$ labelled MamK in polymerization buffer. The labelled proteins had absorption and fluorescence emission maxima of approximately $494 \mathrm{~nm}$ and $519 \mathrm{~nm}$, respectively. The protein concentration and doping percentage were confirmed after measuring the absorbance at 280, 494 and $519 \mathrm{~nm}$. Polymerization was indicated as the changes in the fluorescence intensity of the reaction mixture recording by a Zeiss Axioskop microscope using EMCCD camera (at an excitation wavelength of $493 \mathrm{~nm}$ and an emission wavelength of $517 \mathrm{~nm}$ ) and ZEN image analysis system. The zero value of the fluorescence intensity was taken as the fluorescence of the reaction mixture in the absence of ATP. For the kinetic assays, MamK was added at the designed concentrations to the reaction buffer in a total volume of $10 \mu \mathrm{L}$. The protein concentration range was optimized at $1-10 \mu \mathrm{mol} / \mathrm{L}$, at which the polymerization efficiencies clearly varied and the protein was stable and not prone to aggregation. As described previously (Nurse and Marians, 2013), the maximum intensity values were plotted versus the protein concentration to determine the critical concentration (the $x$-intercept). To calculate the nucleus size and nucleation rate, the logarithm of the maximum rate of polymerization was plotted versus the logarithm of the protein concentration. The nucleus size $(n)$ was estimated as two times the slope of the linear fit, and the $\mathrm{x}$-intercept was estimated as the relative nucleation rate $(K n)$ (Garner et al., 2004; Rivera et al., 2011). The error bars, which represent the average and standard deviations, were obtained by detecting the maximum polymerization rate in triplicate for each protein concentration. Because the ATPase activity of MamK was inhibited at $4^{\circ} \mathrm{C}$ (Fig. 3A), polymerization was assessed using a pelleting assay as described above. The amount of inorganic phosphate $(\mathrm{Pi})$ released was quantified using a modified malachite-green method. All measurements were performed at least in triplicate, and the standard deviations (SD) were calculated from three independent experiments.

\section{Phylogenetic analysis}

Amino acid sequences of various eukaryotic and prokaryotic actins were retrieved from the GenBank databases. Their sources and accession numbers are listed in Table S1. Sequence alignment was conducted using ClustalW, and a maximum-likelihood tree with 100 bootstrap replicates was constructed using MEGA version 4.0 (Tamura et al., 2007).

\section{ACKNOWLEDGEMENTS}

The authors would like to thank Rongcheng Han, Yabing Liu and Xiaolan Zhang for assistance with the fluorescence microscopy, and Jingnan Liang for assistance with transmission electron microscopy. This work was supported by the grants from the National Natural Science Foundation of China (Grants Nos. 31300065 and 41330104) and the Youth Innovation Promotion Association CAS.

\section{ABBREVIATIONS}

HPLC, high-performance liquid chromatography; Mcas, Candidatus Magnetobacterium casensis; MCP, methyl-accepting chemotaxis proteins; MTB, Magnetotactic bacteria; SDS-PAGE, sulfate polyacrylamide gel electrophoresis; TCA, trichloroacetic acid; TEM, transmission electron microscopy.

\section{AUTHOR CONTRIBUTIONS}

T.W. and A.D. designed the study. A.D., L.W. and N.S. designed the experimental program and conducted the experiments. A.D. and L. 
W. analyzed the data obtained from the TEM images. N.S. and Q.S. conducted the experiments to determine the biochemical properties of the ATPase. Data analysis was performed by A.D., L.W., J.W., Z. S. and H.B. A.D. and T.W. wrote the manuscript with suggestions from L.W. and Y.P. All authors reviewed and approved the manuscript.

\section{COMPLIANCE WITH ETHICS GUIDELINES}

Aihua Deng, Wei Lin, Nana Shi, Jie Wu, Zhaopeng Sun, Qinyun Sun, Hua Bai, Yongxin Pan and Tingyi Wen declare that they have no conflict of interest. And this article does not contain any studies with human or animal subjects performed by any of the authors.

\section{OPEN ACCESS}

This article is distributed under the terms of the Creative Commons Attribution 4.0 International License (http://creativecommons.org/ licenses/by/4.0/), which permits unrestricted use, distribution, and reproduction in any medium, provided you give appropriate credit to the original author(s) and the source, provide a link to the Creative Commons license, and indicate if changes were made.

\section{REFERENCES}

Bazylinski D, Lefèvre C, Schüler D (2013a) Magnetotactic bacteria. In: Rosenberg E, DeLong E, Lory S, Stackebrandt E, Thompson F (eds) The prokaryotes. Springer, Berlin, pp 453-494

Bazylinski DA et al (2013b) Magnetococcus marinus gen. nov., sp nov., a marine, magnetotactic bacterium that represents a novel lineage (Magnetococcaceae fam. nov., Magnetococcales ord. nov.) at the base of the Alphaproteobacteria. Int J Syst Evol Microbiol 63:801-808

Bazylinski DA et al (2013c) Magnetovibrio blakemorei gen. nov., sp nov., a magnetotactic bacterium (Alphaproteobacteria: Rhodospirillaceae) isolated from a salt marsh. Int $\mathrm{J}$ Syst Evol Microbiol 63:1824-1833

Bean GJ, Amann KJ (2008) Polymerization properties of the Thermotoga maritima actin MreB: roles of temperature, nucleotides, and ions. Biochemistry 47:826-835

Cabeen MT, Jacobs-Wagner C (2005) Bacterial cell shape. Nat Rev Microbiol 3:601-610

Cabeen MT, Jacobs-Wagner C (2010) The bacterial cytoskeleton. In: Campbell A, Lichten M, Schupbach G (eds) Annual review of genetics. Annual Reviews, Palo Alto, pp 365-392

Carballido LR (2006) The bacterial actin-like cytoskeleton. Microbiol Mol Biol Rev 70:888-909

Cornejo E, Abreu N, Komeili A (2014) Compartmentalization and organelle formation in bacteria. Curr Opin Cell Biol 26:132-138

Derman Al et al (2009) Phylogenetic analysis identifies many uncharacterized actin-like proteins (Alps) in bacteria: regulated polymerization, dynamic instability and treadmilling in Alp7A. Mol Microbiol 73:534-552

Draper O et al (2011) MamK, a bacterial actin, forms dynamic filaments in vivo that are regulated by the acidic proteins MamJ and LimJ. Mol Microbiol 82:342-354
Ent FVD, Amos LA, We JL (2001) Prokaryotic origin of the actin cytoskeleton. Nature 413:39-44

Esue O, Cordero M, Wirtz D, Tseng Y (2005) The assembly of MreB, a prokaryotic homolog of actin. J Biol Chem 280:2628-2635

Faivre D, Schüler D (2008) Magnetotactic bacteria and magnetosomes. Chem Rev 108:4875-4898

Fisher DK, Higgins TJ (1994) A sensitive, high-volume, colorimetric assay for protein phosphatases. Pharm Res 11:759-763

Fujiwara I, Vavylonis D, Pollard TD (2007) Polymerization kinetics of ADP- and ADP-P-i-actin determined by fluorescence microscopy. Proc Natl Acad Sci USA 104:8827-8832

Fusinita VDE, Jakob MJ, Amos LA, Gerdes K, Lowe J (2002) F-actin-like filaments formed by plasmid segregation protein ParM. EMBO J 21:6935-6943

Garner EC, Campbell CS, Mullins RD (2004) Dynamic instability in a DNA-segregating prokaryotic actin homolog. Science 306:10211025

Jogler C et al (2011) Conservation of proteobacterial magnetosome genes and structures in an uncultivated member of the deepbranching Nitrospira phylum. Proc Natl Acad Sci USA 108:11341139

Katzmann E, Scheffel A, Gruska M, Plitzko JM, Schüler D (2010) Loss of the actin-like protein MamK has pleiotropic effects on magnetosome formation and chain assembly in Magnetospirillum gryphiswaldense. Mol Microbiol 77:208-224

Katzmann E et al (2011) Magnetosome chains are recruited to cellular division sites and split by asymmetric septation. Mol Microbiol 82:1316-1329

Kolinko I et al (2014) Biosynthesis of magnetic nanostructures in a foreign organism by transfer of bacterial magnetosome gene clusters. Nat Nanotechnol 9:193-197

Komeili A, Li Z, Newman DK, Jensen GJ (2006) Magnetosomes are cell membrane invaginations organized by the actin-like protein MamK. Science 311:242-245

Lefèvre CT, Bazylinski DA (2013) Ecology, diversity, and evolution of Magnetotactic bacteria. Microbiol Mol Biol Rev 77:497-526

Lefèvre CT, Wu LF (2013) Evolution of the bacterial organelle responsible for magnetotaxis. Trends Microbiol 21:534-543

Lefèvre CT et al (2011) A cultured greigite-producing magnetotactic bacterium in a novel group of sulfate-reducing bacteria. Science 334:1720-1723

Lefèvre CT et al (2012) Novel magnetite-producing magnetotactic bacteria belonging to the Gammaproteobacteria. ISME J 6:440-450

Lin W, Pan YX (2011) Snapping magnetosome chains by asymmetric cell division in magnetotactic bacteria. Mol Microbiol 82:13011304

Lin W, Pan YX (2015) A putative greigite-type magnetosome gene cluster from the candidate phylum Latescibacteria. Environ Microbiol Rep 7:237-242

Lin W, Bazylinski DA, Xiao T, Wu LF, Pan YX (2014a) Life with compass: diversity and biogeography of magnetotactic bacteria. Environ Microbiol 16:2646-2658

Lin W et al (2014b) Genomic insights into the uncultured genus 'Candidatus Magnetobacterium' in the phylum Nitrospirae. ISME J 8:2463-2477

Mayer JA, Amann KJ (2009) Assembly properties of the Bacillus subtilis actin, MreB. Cell Motil Cytoskelet 66:109-118 
Murat D, Quinlan A, Vali H, Komeili A (2010) Comprehensive genetic dissection of the magnetosome gene island reveals the step-wise assembly of a prokaryotic organelle. Proc Natl Acad Sci USA 107:5593-5598

Nurse P, Marians KJ (2013) Purification and characterization of Escherichia coli MreB protein. J Biol Chem 288:3469-3475

Ozyamak E, Kollman JM, Komeili A (2013a) Bacterial actins and their diversity. Biochemistry 52:6928-6939

Ozyamak E, Kollman J, Agard DA, Komeili A (2013b) The bacterial actin MamK: in vitro assembly behavior and filament architecture. J Biol Chem 288:4265-4277

Philippe N, Wu LF (2010) An MCP-Like protein interacts with the MamK cytoskeleton and is involved in magnetotaxis in Magnetospirillum magneticum AMB-1. J Mol Biol 400:309-322

Pollard TD, Cooper JA (2009) Actin, a central player in cell shape and movement. Science 326:1208-1212

Popp D et al (2010) Polymeric structures and dynamic properties of the bacterial actin AlfA. J Mol Biol 397:1031-1041

Rahn LL, Komeili A (2013) The magnetosome model: insights into the mechanisms of bacterial biomineralization. Front Microbiol 4:352

Reimold C, Soufo HJD, Dempwolff F, Graumann PL (2013) Motion of variable-length MreB filaments at the bacterial cell membrane influences cell morphology. Mol Biol Cell 24:2340-2349

Rioux JB et al (2010) A second actin-like MamK protein in Magnetospirillum magneticum AMB-1 encoded outside the genomic magnetosome island. PLoS One 5:e9151

Rivera CR, Kollman JM, Polka JK, Agard DA, Mullins RD (2011) Architecture and assembly of a divergent member of the ParM family of bacterial actin-like proteins. J Biol Chem 286:1428214290

Sahoo N, Beatty W, Heuser J, Sept D, Sibley LD (2006) Unusual kinetic and structural properties control rapid assembly and turnover of actin in the parasite Toxoplasma gondii. Mol Biol Cell 17:895-906

Schüler D (2008) Genetics and cell biology of magnetosome formation in magnetotactic bacteria. FEMS Microbiol Rev 32:654-672

Seignovert LD, Cariot G, Vuillard L (2004) The toxicity of recombinant proteins in Escherichia coli: a comparison of overexpression in BL21(DE3), C41(DE3), and C43(DE3). Protein Expr Purif 37:203-206

Shih YL, Rothfield L (2006) The bacterial cytoskeleton. Microbiol Mol Biol Rev 70:729-754

Sonkaria S et al (2012) Insight into the assembly properties and functional organisation of the magnetotactic bacterial actin-like homolog, MamK. PLoS One 7:e34189

Szwedziak P, Wang Q, Freund SMV, Loewe J (2012) FtsA forms actin-like protofilaments. EMBO J 31:2249-2260

Tamura K, Dudley J, Nei M, Kumar S (2007) MEGA4: molecular evolutionary genetics analysis (MEGA) software version 4.0. Mol Biol Evol 24:1596-1599

Taoka A, Asada R, Wu LF, Fukumori Y (2007) Polymerization of the actin-like protein MamK, which is associated with magnetosomes. J Bacteriol 189:8737-8740

Webb MR (1992) A continuous spectrophotometric assay for inorganic phosphate and for measuring phosphate release kinetics in biological systems. Proc Natl Acad Sci USA 89:4884-4887

Zhu KL et al (2010) Isolation and characterization of a marine magnetotactic spirillum axenic culture $\mathrm{QH}-2$ from an intertidal zone of the China Sea. Res Microbiol 161:276-283 